\title{
A FORMAÇÃO CONTINUADA DE PROFESSORES DOS ANOS INICIAIS DO ENSINO FUNDAMENTAL NO CONTEXTO DO ENCONTRO E DAS TROCAS INTERGERACIONAIS
}

\author{
Tiago Henrique da Silva RAMOS* \\ Elmir de ALMEIDA*
}

RESUMO: O presente trabalho baseia-se em uma pesquisa de Mestrado em andamento que tem como objetivo analisar que relaçóes formativas são estabelecidas entre os professores iniciantes - jovens, recém-formados ou com no máximo cinco anos de experiência docente - e professores experientes - na faixa etária de quarenta anos ou mais e com cerca de quinze anos ou mais de docência, dentro de uma escola de ensino fundamental (anos iniciais), concebida como um espaço formativo. Tem-se como hipótese que estes grupos realizam trocas e transmissóes intergeracionais, e a partir delas agregam conhecimentos e valores à sua formação acadêmica, profissional e pessoal, já que possuem pertencimentos geracionais distintos e realizaram sua formação inicial para docência em diferentes tempos e espaços, respaldados por diferentes versóes da lei de diretrizes e bases da educação nacional. Há que se considerar que a presença de professores de geraçóes distintas, em um mesmo espaço escolar, pode possibilitar momentos de compartilhamento de experiências e análise dos problemas do cotidiano da escola a partir de olhares diferenciados,

\footnotetext{
* Mestre em Educação. USP - Universidade de São Paulo. Faculdade de Filosofia de Filosofia, Ciências e Letras - Programa de Pós-Graduação em Educação. Ribeirão Preto - SP Brasil. 14090-901 - tiagoramos2@terra.com.br.

** Professor Doutor. USP - Universidade de São Paulo. Faculdade de Filosofia de Filosofia, Ciências e Letras - Programa de Pós-Graduação em Educação. Ribeirão Preto - SP - Brasil. 14090-901 - elmir@ffclrp.usp.br.
} 
frutos de sujeitos com formação histórica, social e profissional distintas. Desta maneira, a relação destes professores em um contexto complexo como a escola pode suscitar atitudes de solidariedade, crescimento mútuo e colaboração.

PALAVRAS-CHAVE: Geração. Formação continuada de professores. Escola.

A formação de professores que atuam na educaçáo básica em geral, e nos anos iniciais do ensino fundamental em particular, é uma das questóes centrais no interior dos debates que ocorrem no campo da educação escolar e também no das políticas públicas educacionais, pois, envolve questóes ético-políticas e acadêmico-científicas acerca da ordem societária e das novas geraçóes de indivíduos que desejamos formar, em médio ou longo prazo. Sobre tal questáo, partimos do pressuposto que a socializaçáo e formação profissional de professores para a educação escolar não se reduz e se esgota no interior do universo acadêmico - a formação inicial, ela é e deve ser contínua ${ }^{1}$, implicando a ação consciente e racionalmente deliberada de múltiplos e diferenciados agentes sociais e institucionais, ancorados em diferentes espaços-tempos de socialização e formação profissional (TANURI, 2000; TARDIF; RAYMOND, 2000; AZANHA, 1998, 2004, 2006; SAVIANI, 2004, 2009; SCHWARTZMAN, 2005).

Tardif e Raymond (2000), ao refletirem sobre "os saberes e os tempos de aprendizagem" que contribuem ao trabalho dos professores da educação básica, defendem a ideia de que os "saberes" necessários ao exercício da docência e à produçáo identitária dos professores decorrem de múltiplas e variadas "fontes sociais", os quais contribuem para que os indivíduos vivenciem distintos "modos de integração no trabalho docente" (TARDIF; RAYMOND, 2000, p. 215). No modelo tipológico de "saberes" que contribuem ao savoir faire dos professores e a sua integração no universo profissional do magistério, Tardif e Raymond (2000) lançam mão dos conceitos de "socialização primária" e "socialização secundária" para assinalarem que

Adotamos o termo formação continuada de professores como sinônimo de formaçấo permanente ou formação continuada em serviço.

2 Ao utilizarem tais conceitos, Tardif e Raymond (2000) fazem uma referência direta ao clássico trabalho de Peter Berger e Thomas Luckmann, A construção social da realidade. 
[...] os diversos saberes dos professores estão longe de serem todos produzidos diretamente por eles, [...] vários deles são de um certo modo "exteriores" ao ofício de ensinar, pois provêm de lugares sociais anteriores à carreira propriamente dita ou fora do trabalho cotidiano. [...] Alguns provêm da família do professor, da escola que o formou e de sua cultura pessoal; outros vêm das universidades; outros sáo decorrentes da instituiçáo ou do estabelecimento de ensino (programas, regras, princípios pedagógicos, objetivos, finalidades etc.); outros, ainda, provêm dos pares, dos cursos de reciclagem etc. Nesse sentido, o saber profissional está, de um certo modo, na confluência entre várias fontes de saberes provenientes da história de vida individual, da sociedade, da instituição escolar, dos outros atores educativos, dos lugares de formação etc (TARDIF; RAYMOND, 2000, p. 215, grifo nosso).

O presente trabalho de pesquisa partilha das análises de Tardif e Raymond (2000) acima evocadas, e se dedica a análise dos "saberes" que contribuem à formação e integração profissional do professor obtidos em processos de "socialização secundária". Em outras palavras, o estudo tem por objetivo compreender os saberes que professores do ensino fundamental logram conquistar nos interstícios das relaçôes cotidianas que eles estabelecem com os pares no interior do "mundo escolar" (AZANHA, 2004; 2006), sobretudo no âmbito das trocas ou transmissôes intergeracionais.

As perguntas centrais de nossa pesquisa foram assim constituídas: 1) Quais são os conteúdos das trocas e transmissôes socializadoras que ocorrem entre docentes pertencentes a distintas geraçóes, atuantes nos anos iniciais do ensino fundamental? Do ponto de vista dos docentes que integram as novas geraçóes, as trocas ou transmissóes intergeracionais que se configuram no cotidiano escolar contribuem ao savoir faire e a integração dos mesmos na esfera do trabalho do magistério, tanta na sala de aula como no espaço-tempo mais amplo da escola?

A pesquisa vem sendo desenvolvida em escola pública de rede municipal de ensino de localidade urbana de porte médio, situada no interior do estado de Sáo Paulo. Trata-se de estudo de abordagem qualitativa que concebe a escola como "grupo social" produtor de sociabilidades próprias e dotado de autonomia relativa (CÂNDIDO, 1964; AZANHA, 1998, e que adotou os conceitos de geração e transmissóes 
intergeracionais, como operadores analíticos fundamentais para a apreensão e análise das trocas de "saberes" que ocorrem entre os docentes de distintas geraçóes no interior da unidade escolar campo-empírico da pesquisa (MANNHEIM, 1993; ATTIAS-DONFUT; LAPIERRE, 1994; FORQUIN, 2003; WELLER, 2010; TOMIZAKI, 2005).

\section{A fecundidade do conceito mannheimiano de geração para a formulação do objetivo de estudo}

Nas Ciências Sociais, o conceito de geração não é unívoco, e como sublinha Forquin (2003), ele pode ser usado em pelo menos três acepçôes: como genealogia familial, como classe de idades ou no sentido histórico-social e cultural. Segundo este mesmo autor, na perspectiva genealógica familial, o conceito enfeixa "o sentido de filiação, ou [...] de grau de filiação (primeira, segunda, terceira geração...) a partir de um indivíduo tomado como origem" (FORQUIN, 2003, p.3). Quando referido a classes de idades, o conceito enfatiza o critério etário de determinados indivíduos ou as coortes, ou seja, o destaque recai sobre sujeitos que nasceram na mesma data ou em um período cronológico próximo, por tais razóes é possível fazer referências a "jovem geração", as "gerações adultas", a "velha" ou a "antiga geração" etc. Na perspectiva histórico-social ou cultural, o conceito refere-se às experiências concretas e subjetivas dos indivíduos ao designar "[...] um conjunto de pessoas que nasceram mais ou menos na mesma época e que têm em comum uma experiência histórica idêntica e/ou uma proximidade cultural" (FORQUIN, 2003, p.3).

Tendo em vista que o estudo que desenvolvemos tem por objetivo investigar a formaçáo continuada e em serviço de professores a partir das trocas ou transmissóes intergeracionais, e considerando que os professores com os quais temos dialogado são indivíduos-profissionais que possuem idades distintas, formados por diferentes geraçóes de Lei de Diretrizes e Bases da Educação Nacional - LDBENs e em tempos histórico-culturais distintos, adotamos com referência teórica o conceito sociológico de geração formulado por Karl Mannheim (1993), em seu clássico El problema de las generaciones. 


\section{Breves consideraçóes sobre o conceito de geraçóes em Mannheim}

Para Mannheim (1993) a compreensão sociológica do fenômeno da(s) geração(ôes) ou da "conexão geracional" começa quando verificamos que os fatores biológicos têm significância sociológica: a geração é um tipo peculiar de "posição social": [...] ahí está la primera tarea - para ir más allá de los fenómenos elementales - compreender la conexión generacional como un tipo especifico de posición social' (MANNHEIM, 1993, p.209). Entretanto, Mannheim observa que a "conexão geracional", contém apenas potencialidades, isto é, ela pode tornar-se uma realidade histórica e sociológica objetiva ou, ainda, pode ser suprimida ou materializar-se em outras forças sociais. Assim, para falarmos de geração e que os indivíduos ocupam uma mesma "posição geracional", é preciso ter nascido no mesmo espaço-tempo histórico social, assim:

Nos hemos acercado ya lo suficiente al fenómeno sobre el que vamos a tratar a partir de ahora, como para que tengamos que reconocer que la mera contemporaneidad biológica no basta para constituir una posición generacional afin. Para estar incluido en una posición generacional, para soportar pasivamente los frenos y las oportunidades de esa posición, pero también para poder utilizarlos activamente, tiene uno que haber nacido en el mismo ámbito histórico-social —en la misma comunidad de vida histórica - y dentro del mismo periodo (MANNHEIM, 1993, p. 221).

Além do pertencimento a um mesmo espaço-tempo histórico e social, para falarmos de uma geração ou de uma "conexão geracional", é necessário que os sujeitos que nasceram em data semelhante também participem de um "destino comum" no interior de um espaço histórico e social preciso.

Sin embargo, la conexión generacional es algo más que esa mera presencia circunscrita en una determinada unidad histórico-social. Para que se pueda hablar de una conexión generacional tiene que darse alguna otra vinculación concreta. Para abreviar, podría especificarse esa adhesión como una participación en el destino común de esa unidad histórico-social (MANNHEIM, 1993, p. 221, grifos do autor). 
A partir desse conjunto de elementos, e superando a abordagem positivista e histórico-romântica alemã, Mannheim (1993) define o conceito de geração afirmando que ela só existe quando há um vínculo real entre os contemporâneos e os coetâneos, tanto do ponto de vista dos conteúdos histórico e culturais, como do ponto de vista intelectual

[...] sólo hablaremos, por lo tanto, de una conexión generacional cuando los contenidos sociales reales y los contenidos espirituales establecen - precisamente en los terrenos de lo que se ha desestabilizado y de lo que está em renovación - un vínculo real entre los individuos que se encuentran en la misma posición generacional (MANNHEIM, 1993, p. 222).

É pelas razôes acima mencionadas que Mannheim (1993) sublinhou o fato de que os indivíduos que pertencem à mesma geração ou partilham de uma "conexão geracional", podem experimentar a contemporaneidade dos não contemporâneos ou a não contemporaneidade dos coetâneos, formando, dessa maneira, distintas "unidades de geração". Em outras palavras, ele observa que os indivíduos ou coletivos que nasceram no mesmo ano, que vivem no mesmo espaço-tempo histórico e social e experimentam a mesma geraçáo de realidade - conteúdos culturais ou intelectuais, partilham uma "conexão geracional", entretanto, dentro de cada geração, os indivíduos ou grupos que "[...] emplean essas vivencias de modos diversos constituyen, en cada caso, distintas 'unidades generacionales' en el ámbito de una misma conexión generacional' (MANNHEIM, 1993, p. 223).

Mannheim (1993) destaca, também, que os ritmos da continuidade ou da mudança histórica estão vinculados às relaçóes e trocas/ transmissóes socializadoras que os mais novos estabelecem com os integrantes das geraçôes mais adultas ou mais experientes. É preciso salientar ainda que o autor pontua o caráter interativo das geraçóes, destacando as trocas intergeracionais e as diferentes formas de aprendizagens: além de o mais novo aprender com o mais velho, este também aprende com o primeiro. Desta forma, se é possível admitir que no encontro e nas trocas intergeracionais haja tensôes e conflitos, neles também é possível ocorrer a cooperação e a solidariedade. Nos termos de Forquin (2003), nas relaçóes que estabelecem indivíduos pertencentes a gerações distintas há intercâmbios, e no interior das relaçôes 
que eles estabelecem há espaços para trocas e transmissões intergeracionais que podem gerar aprendizagens mútuas, ou provocarem conflitos ou atitudes apáticas.

$\mathrm{E}$ aqui podemos estabelecer um encontro entre as contribuiçóes que Tardif e Raymond (2000) e Mannheim (1993) oferecem ao nosso estudo, pois segundo aqueles autores os saberes que informam e orientam as açóes profissionais dos professores no interior da escola e da sala aula provém de fontes e lugares sociais "exteriores" e "interiores" ao ofício de ensinar; se alguns deles são devidos aos agentes e processos de "socialização primária" - a família, outros decorrem de agentes educativos e processos de "socialização secundária", entre eles "a instituiçáa” ou o "estabelecimento de ensino" nas quais os professores trabalham, ou ainda, os "saberes" podem decorrer das interaçôes e trocas que há entre "os pares" (TARDIF; RAYMOND, 2000, p.215). Nesta última possibilidade é preciso admitir que no interior do conjunto de professores de um mesmo estabelecimento de ensino, os indivíduos têm pertencimentos etários distintos, foram socializados e formados para o exercício da profissão no magistério em distintas geraçôes de realidade histórica e sociocultural - inclusive do ponto de vista da legislação educacional. Assim, é plausível afirmar que os "saberes docentes" que decorrem das relaçóes entre "os pares" derivam do encontro e das transmissóes intergeracionais. Trocas que permitem mútuos processos socializadores ou de "aprendizagens" e que gestam contextos de tensóes, conflitos, apatia ou, ainda, cooperação e solidariedade. São elas que contribuem à transmissão da herança do savoir faire dos professores, seja no sentido da continuidade dos códigos e da cultura que dâo materialidade a profissão do magistério, seja no sentido de produzir mudanças nos códigos e na cultura mesma da profissão docente e nos modos como eles atuam no interior do "mundo escolar" (AZANHA, 2004; 2006).

Sendo assim, nas escolas, podemos encontrar diferentes grupos geracionais de professores e, um dos fatores utilizados na conformação de cada um destes coletivos é a formação acadêmica para o exercício da docência. É possível que esteja atuando na mesma instituição escolar professores formados sob o contexto das diferentes versões da Lei de Diretrizes e Bases da Educaçáo Nacional (LDBEN), o que configura espaços e tempos formativos diversificados em relação ao magistério dos anos iniciais do ensino fundamental, que na escola se encontram, 
podendo promover trocas, aprendizagens e crescimento mútuo, como atitudes de apatia, repulsa ou conflitos.

\section{Alguns resultados atingidos pelo estudo até o momento}

$\mathrm{Na}$ escola pública que têm servido de campo empírico ao nosso estudo foi possível identificar dois grupos de docentes que pertencem a geraçóes etárias e histórico-sociais distintas: um grupo é formado por docentes que têm entre 24 e 29 anos de idade, o outro é conformado por professores com idades entre 41 e 60 anos de idade.

Os dados preliminares conseguidos através de questionários respondidos pelos dois grupos de professores focados neste estudo nos apontam a formação de duas geraçôes distintas tomando como referência principal os espaços e tempos em que vivenciaram a sua formaçáo para o exercício da docência. A geração mais experiente é formada por mulheres que frequentaram o antigo segundo grau (atual ensino médio) com habilitação para o Magistério, assim que se formaram já passaram a atuar como professoras e depois cursaram a graduação em Pedagogia. Já, a geraçáo jovem é formada por professoras que conquistaram sua formação para a docência através do curso de Pedagogia.

No primeiro conjunto de docentes, a realidade de formação acadêmica para o exercício do magistério é mais diversificada, pois verificamos a presença de docentes que obtiveram a formação inicial nos âmbitos do ensino médio - "curso normal" ou da "habilitação específica ao magistério", e do ensino superior posteriormente; professores que foram academicamente formados no contexto histórico e cultural de vigência da segunda geração de LDBENs, ou seja, a Lei Federal $n^{\circ} 5.692 / 1971$ (BRASIL, 1971). No segundo grupo temos professores que atuam nos anos iniciais do ensino fundamental que foram formados academicamente para o exercício profissional do magistério no ensino superior - em faculdades privadas em sua maioria, portanto, do ponto de vista histórico-social, no contexto da terceira geração de LDBs, a Lei Federal no 9.394/1996 (BRASIL, 1996), assim como das políticas públicas educacionais das últimas três décadas.

A maior parte das professoras da geração com mais experiência docente são efetivas, aprovadas em concurso público e atuam na escola pesquisada desde a sua fundação. Algumas das professoras da geração mais jovem são contratadas temporariamente, através de processo sele- 
tivo, realizado pela Prefeitura Municipal e estão tendo sua primeira atuação profissional como docentes nos anos iniciais do ensino fundamental.

Outro dado importante provém de nossas observaçóes de alguns momentos escolares em que os professores estão envolvidos, como o horário de trabalho pedagógico coletivo (HTPCs). O acompanhamento desses encontros tem nos mostrado que este tempo destinado ao aprimoramento ou capacitaçáo em serviço dos professores, acaba sendo usado em sua maior parte como espaço para a divulgação de recados, broncas ou um momento livre, sem um direcionamento específico voltado às discussões pedagógicas ou de interesse da unidade escolar ou dos professores.

Mesmo assim, nossas observaçóes iniciais destes momentos coletivos que acontecem no interior da escola também nos revelam experiências de trocas e aprendizagens mútuas entre professores das diferentes geraçôes (intergeracionais) e também entre aqueles que possuem um mesmo pertencimento geracional. Presenciamos ainda reflexôes sobre a profissão de professor, as ingerências advindas da Secretaria Municipal de Educação, as dificuldades enfrentadas etc.

Convivendo juntas no espaço escolar, as duas gerações compartilham experiências comuns e a partir de suas vivências anteriores e do que aprendem e trocam mutuamente com seus pares são geridas novas possibilidades de olhar e pensar as relaçôes sociais e pedagógicas estabelecidas na escola.

\section{CONTINUOUS EDUCATION OF TEACHERS OF ELEMENTARY SCHOOL (EARLY YEARS) KEY IN THE CONTEXT OF MEETING AND INTERGENERATIONAL EXCHANGES}

ABSTRACT: This study is based on a Master's research in progress that aims to analyze that formative relationships are established between beginning young teachers, recently graduated or with a maximum of five years of teaching experience - and experienced teachers - aged forty years or more and about fifteen or more years of teaching, within an elementary school (early years), conceived as a training space. It has been hypothesized 
that these groups conduct exchanges and intergenerational transmissions, and from them add knowledge and values to their academic, professional and personal education as they have distinct generational belongings and made their initial training for teaching at different times and spaces, supported by different versions of the Law of guidelines and bases for national education. It should be considered that the presence of different generation teachers in the same school environment, may enable experience sharing moments and analysis of school everyday problems from different points, fruit of subjects with historical background, social and professional distinct. In this way, the relationship of these teachers in a complex context as the school may raise attitudes of solidarity, mutual growth and cooperation.

KEY WORDS: Generation. Continuing Education of Teachers. School

\section{REFERÊNCIAS}

ATTIAS-DONFUT, C.; LAPIERRE, N. La dynamique des générations. Communications, Paris, v. 59, n. 59, p. 5-13, 1994.

AZANHA, J. M. P. A formaçáo do professor e outros escritos. São Paulo: SENAC, 2006.

. Uma reflexão sobre a formação do professor da escola básica. Educação e Pesquisa, São Paulo, v.30, n.2, p. 369-378, maio/ago. 2004.

Proposta pedagógica e autonomia da escola. 1998. Disponível em: <http://www3.fe.usp.br/secoes/inst/novo/acervo_jmpa /PDF_SWF/78.pdf>. Acesso em: 14 dez. 2015.

BRASIL. Lei Federal no. 9.394, de 20 de dezembro de 1996. Estabelece as diretrizes e bases da educação nacional. Diário Oficial da Uniáo, Brasília, 1996. Disponível em: <http://portal.mec.gov.br/ arquivos/pdf/ldb.pdf>. Acesso em: 9 dez. 2015.

. Lei Federal no 5.692/71, de 11 de agosto de 1971. Fixa diretrizes e bases para o ensino de $1^{\circ}$ e $2^{\circ}$ graus, e dá outras providências. Diário Oficial da Uniáo, Brasília, 1971. Disponível em: 
<http://www.planalto.gov.br/ccivil_03/Leis/L5692.htm>. Acesso em: 30 nov. 2015.

CANDIDO, A. A estrutura da escola. In: PEREIRA, L.; FORACCHI, M. M. Educaçáo e Sociedade: Leituras de Sociologia da Educação. São Paulo: Nacional, 1964. p. 107-128.

FORQUIN, J. Relaçôes entre geraçóes e processos educativos: transmissões e transformaçóes. In: CONGRESSO INTERNACIONAL CO-EDUCAÇÃO DE GERAÇÕES SESC, out. 2003, São Paulo. Anais... São Paulo, 2003. Disponível em: <http://www.sescsp.org.br/ sesc/images/upload/conferencias/83.rtf>. Acesso em: 20 set. 2015.

MANNHEIM, K. El problema de las geraciones. Revista Española de Investigaciones Sociológicas, Madrid, n. 62, p. 193-244, 1993.

SAVIANI, D. Formação de professores: aspectos históricos e teóricos do problema no contexto brasileiro. Revista Brasileira de Educaçáo, Rio de Janeiro, v. 14, n. 40, p. 143-155, jan/abr. 2009.

O espaço acadêmico da Pedagogia no Brasil: perspectiva histórica. Paidéia, Ribeirão Preto, v. 14, n. 28, p. 113-124, 2004.

SCHWARTZMAN, S. Os desafios da educação no Brasil. In: ROCK, C.; SCHWARTZMAN, S. (Ed.). Os desafios da educaçáo no Brasil. Rio de Janeiro: Nova Fronteira, 2005.p. 9-50.

TANURI, L. M. História da formação de professores. Revista Brasileira de Educaçáo, Rio de Janeiro, n. 14, p. 61-88, mai./ago. 2000.

TARDIF, M; RAYMOND, D. Saberes, tempo e aprendizagem do trabalho no magistério. Educaçáo \& Sociedade, Campinas, v. 21, n. 73, dez. 2000.

TOMIZAKI, K. A. Ser metalúrgico no ABC: rupturas e continuidades nas relaçóes intergeracionais da classe trabalhadora. 2005. 305f. Tese (Doutorado em Educação) - Faculdade de Educação, Universidade Estadual de Campinas, Campinas, 2005.

WELLER, W. A atualidade do conceito de gerações de Karl Mannheim. Sociedade e Estado, Brasília, v. 25, n. 2, mai./ago. 2010. 
